\title{
Study on Antifungal Ability of Water Soluble Chitosan Against Green Mould Infection in Harvested Oranges
}

\author{
Le Thanh Long ${ }^{1}$, Nguyen Thi Thuy Tien ${ }^{1}$, Nguyen Hien Trang ${ }^{1}$, Tran Thi Thu Ha ${ }^{1} \&$ Nguyen Minh Hieu ${ }^{1}$ \\ ${ }^{1}$ Hue University of Agriculture and Forestry, Viet Nam \\ Correspondence: Le Thanh Long, Hue University of Agriculture and Forestry, 102 Phung Hung, Hue, Viet Nam. \\ Tel: 84-090-515-1415. E-mail: ltlongnl@gmail.com
}

Received: May 20, 2014 Accepted: June 11, 2014 Online Published: July 15, 2014

doi:10.5539/jas.v6n8p205 URL: http://dx.doi.org/10.5539/jas.v6n8p205

\begin{abstract}
Effect of water-soluble chitosan (WSC) on green mould disease caused by Penicillium digitatum P4 was investigated in vitro and in vivo. Results of the experiments showed that $P$. digitatum $\mathrm{P} 4$ growth was much inhibited by WSC and inhibitory effect increased as WSC concentration increased. In vitro test results indicated that complete inhibition of spore germination and mycelial growth were observed in the medium containing 1 $\mathrm{mg} / \mathrm{ml}$ WSC. In the in vivo study, WSC treatments significantly reduced disease incidence and lesion diameter of green mould disease on orange fruits. After 8 days of inoculation, the lesion diameter of orange fruits coated by $0.5 \%, 1 \%, 1.5 \%$ and $2 \%$ WSC were $5.49 \mathrm{~cm}, 5.01 \mathrm{~cm}, 3.22 \mathrm{~cm}$ and $1.87 \mathrm{~cm}$, respectively, which smaller than that of control fruits. Biochemical experiments demonstrated that the activities of the main defense-related enzymes in flavedo tissue including chitinase and $\beta$-1,3-glucanase were enhanced by both $P$. digitatum $\mathrm{P} 4$ infection treatment and challenged with $P$. digitatum $\mathrm{P} 4$ and treated with WSC treatment. However, these enzymes of samples inoculated with $P$. digitatum only were lower than samples inoculated with $P$. digitatum $\mathrm{P} 4$ and treated with $2 \%$ WSC concentration. These findings suggest that the in vitro and in vivo effects of WSC on controlling green mould disease may be associated with direct antifungal activities and the elicitation of biochemical defense responses in fruit.
\end{abstract}

Keywords: antifungal, elicitor, green mould disease, Penicillium digitatum, water-soluble chitosan

\section{Introduction}

Citrus (Citrus sinesis L.) is consumed as fresh fruit and juice and is widely appreciated for its nutritional value and excellent taste. It is one of the most commonly produced and traded fruit crops in the world (Korsten \& Taverner, 2012). Vietnam is one of the world's largest orange producers, ranked $20^{\text {th }}$ in 2012 (Food and Agriculture Organization Statistics, 2012) and famous for many delicious orange species. Valencia 2 orange from Nghe An Province is one of the good species with juiciness and sweet with a little acidic flavor. Citrus spp. are prone to be attacked by more than 100 diseases, among them, green mould caused by the fungus Penicillium digitatum can be responsible for up to $90 \%$ of output losses during post-harvest handling, particularly in production areas characterized by low summer rainfall. $P$. digitatum is considered as one of the most important post-harvest diseases of citrus fruit (Naqvi, 2004; Korsten \& Taverner, 2012). For many decades, synthetic fungicides have been the main method of citrus post-harvest disease control. Although the great advantages they have brought to agricultural development, the increasing public concerns regarding health hazards and environmental pollution from chemical residues and the proliferation of resistant strains of pathogens have necessitated the intensive search for alternative strategies for the control of postharvest pathogens (Narayanasamy, 2006).

Chitosan, a deacetylated derivative of chitin, mainly consists of glucosamine units, 2-amino-2 deoxy- $\beta$-D-glucose. This natural compound is biodegradable, nontoxic and biocompatible and has diverse applications in agriculture, one among which the control of fungal diseases in crops of agricultural interest (Hernández-Lauzardo, Valle, \& Guerra-Sánchez, 2011) has shown to be particularly useful in both pre- and post-harvest disease control due to its dual functions: antifungal activities and elicitation of host defense responses (Xu, Zhao, Han, \& Du, 2007; Bautista-Banos et al., 2006; Hernandez-Lauzardo et al., 2011). Chitinase and $\beta$-1,3-glucanase are two kinds of pathogenesis-related protein and stimulated by infection and in response to chitosan (Barkai-Golan, 2001). However, its high viscosity and insolubility in neutral aqueous solution restrict 
chitosan uses in practice (Xu et al., 2007).

Recent studies on chitosan have attracted interest in converting chitosan to water-soluble chitosan (Xu et al., 2007). Water-soluble chitosan, obtained by hydrolysis or degradation of chitosan, is not only water-soluble but also has shown to be more effective than chitosan in inhibiting pathogen growth and eliciting multiple plant defense responses (Yan et al., 2011). But up to now, there have been few articles that reported about the use of WSC for controlling postharvest disease. Considering the potential of WSC as an antifungal agent, the objective of this study was to investigate the in vitro and in vivo effects of WSC on Penicillium digitatum development. In addition, the activities of antifungal hydrolases were also determined to evaluate the elicitation effect of WSC.

\section{Materials and Methods}

\subsection{Penicillium Digitatum Isolation and Inoculum Preparation}

The Penicillium digitatum strain P4 was isolated from naturally infected orange fruits showing typical green mould symptom. From the side of infected tissue, the hyphae was taken, placed on Petri dishes (6 cm in diameter) containing PDA medium (Himedia, India) and incubated at $25{ }^{\circ} \mathrm{C}$. Pure culture was obtained by repeatedly isolation on PDA medium. According to Koch's postulates, the orange fruit was infected with this microorganism, and the typical green mould symptom appeared again (Meng, Yang, Kennedy, \& Tian, 2010). This $P$. digitatum P4 strain was identified based on morphology and analysis of 28s rRNA gene sequencing methods.

The fungus identified as $P$. digitatum P4 was maintained on PDA medium. Conidial suspension of the pathogen was prepared by flooding the 14-day-old culture dishes of $P$. digitatum $\mathrm{P} 4$ with sterile distilled water containing $0.01 \%$ Tween 80 and then filtered through four layers of sterile cheesecloth. The spore concentrations were determined by haemacytometer and adjusted to $10^{5}$ spore/ml (Meng et al., 2010).

\subsection{Fruits}

The mature yellow Valencia 2 (V2) oranges were hand-harvested from orchard in Quy Hop District, Nghe An Province, Vietnam and transported immediately to the laboratory. Fruits were selected based on their size, uniformity, color, shape and the absence of physical injuries or disease infections. Before being used, the fruits were cleaned with tap water, then the surface disinfected by $70 \%$ ethanol and finally washed again with sterile distilled water and dried by air (Meng et al., 2010).

\subsection{Preparation of Water-Soluble Chitosan}

Water-soluble chitosan with an average molecular weight of 40-50 kDa was prepared according to our method (Le, Nguyen, Trang, \& Vu, 2013).

\subsection{In vitro Antifungal Assay of Water-Soluble Chitosan Against P. digitatum P4}

\subsubsection{Effect of WSC on Spore Germination of P. digitatum P4}

Germination of spore was determined by cavity slide technique (Cronin, Yohalem, Harris, \& Andrews, 1996). A $10 \mu \mathrm{l}$ of conidial suspension of $P$. digitatum P4 (adjusted to $10^{5} \mathrm{spore} / \mathrm{ml}$ ) was pipetted into a cavity slide containing $40 \mu \mathrm{l}$ of each tested WSC concentration. Cavity slide containing distilled water served as the control. The slide was covered by cover slip and kept at $25^{\circ} \mathrm{C}$. After $24 \mathrm{~h}$ incubation, the slide was observed for conidial germination under a light microscope at 40 magnification. A conidium was considered as germinated when its germ tube had exceeded half the length of the spore. Each treatment was replicated five times. The percentage of germination inhibition was calculated according to Cronin et al. (1996).

\subsubsection{Effect of WSC on Mycelial Radial Growth}

$6 \mathrm{ml}$ PDA sterile medium amended with WSC at different concentrations: $0.2,0.4,0.6,0.8 \mathrm{and} 1 \mathrm{mg} / \mathrm{ml}$ were poured onto sterile Petri dishes $(6 \mathrm{~cm}$ in diameter). Mycelial plugs $(5 \mathrm{~mm}$ in diameter) from the margin of two-week-old cultures of P.digitatum P4 were placed on the center of the prepared dishes and then incubated at $25^{\circ} \mathrm{C}$ in the dark. Unamended PDA plates served as controls. Each treatment contained five replicates. Inhibitory effect of mycelial growth was determined by measuring colony diameter until colony of control sample reached the edge of the plate. The percentage inhibition of radial growth was calculated according to Al-Hetar, Zainal Abidin, Sariah, and Wong (2010).

The $\mathrm{EC}_{50}$ (the effective concentration inhibiting growth by $50 \%$ ) and $\mathrm{MIC}_{90}$ (the minimum concentration showing over $90 \%$ inhibition of mycelial growth) values were determined by probit analysis.

\subsubsection{Effect of WSC on Mycelial Growth in Broth Cultures}

In this experiment, $100 \mathrm{ml}$ PDB (Potato Dextrose Broth, Himedia, India) medium containing various 
concentrations of WSC ( 0 (control), 0.2, 0.4, $0.6,0.8$ and $1 \mathrm{mg} / \mathrm{ml}$ ) were prepared in $250 \mathrm{ml}$ flasks. $1 \mathrm{ml}$ conidial suspension of $P$. digitatum $\mathrm{P} 4$ at a concentration of $10^{5} \mathrm{spore} / \mathrm{ml}$ was added to each flask and then shaken at 25 ${ }^{\circ} \mathrm{C}$ for 14 days. The mycelium were filtered, dried at $100{ }^{\circ} \mathrm{C}$ for 24 hours and weighed. The inhibition effect of WSC based on dried biomass was estimated according to Al-Hetar et al. (2010). Each experiment was carried out in five replicates.

\subsection{In vivo Antifungal Assays of WSC Against Green Mould Disease}

The selected orange fruits were dipped in $0.5,1.0,1.5$ and $2.0 \%$ WSC solution for 1 minute, respectively. The fruits treated with distilled water were used as control. After being air-dried for 3 hours, each fruit was wounded with a dissecting needle ( $2 \mathrm{~mm}$ long and $1 \mathrm{~mm}$ wide) at two sites on the opposite sides of the equator. Then $10 \mu 1$ conidial suspension of $P$. digitatum $\mathrm{P} 4$ at $10^{5} \mathrm{spore} / \mathrm{ml}$ was pipetted to each wound. The treated fruits were air-dried again for 1 hour and then put in $200 \mathrm{~mm} \times 130 \mathrm{~mm} \times 50 \mathrm{~mm}$ plastic boxes with sterile water to maintain a high relative humidity (about $95 \%$ ) and stored at $25^{\circ} \mathrm{C}$ (Meng et al., 2010). The diameter lesion was measured by digital micrometer every two days for eight days (Jitareerat, Paumchai, Kanlayanarat, \& Sangchote, 2007). Each treatment had five replicates.

\subsection{Determination of Defense-Related Enzymes: Chitinase and $\beta-1,3-$-Glucanase}

Fruits used for measuring defense-related enzyme activities were also prepared and divided into 3 groups. Fruits in first group were dipped into a $2 \%$ WSC solution and inoculated with $P$. digitatum P4. The second group was inoculated with mould only and the untreated WSC and uninoculated fruits were served as a control group. Chitinase and $\beta-1,3$-glucanase were assayed from flavedo tissues of orange fruits. Flavedo material was peeled from the border of macerated tissue to the healthy zone every two days for eight days with sterile knife (Fajardo, McCollum, McDonald, \& Mayer, 1998).

Enzymes were extracted at $4{ }^{\circ} \mathrm{C}$ by using the method of Cao and Yiang (2006) with slight modifications. Flavedo tissues were sliced, frozen in liquid nitrogen, and ground with a mortar and pestle. $20 \mathrm{mg}$ of ground tissues were homogenized with $400 \mu \mathrm{l}$ of $0.05 \mathrm{M}$ natri acetate buffer $(\mathrm{pH}=5.2)$. The suspension was pelleted by centrifugation at $14000 \mathrm{rpm}$ for 15 minutes at $4{ }^{\circ} \mathrm{C}$. The supernatant phase was collected to determine chitinase and $\beta$-1,3-glucanse activities.

Assay of $\beta$-1,3-glucanase activity was carried out according to the method of Abeles and Forrence (1970) with some modifications. The mixture of $50 \mu \mathrm{l}$ of extracted flavedo enzyme and $50 \mu \mathrm{l}$ of laminarin (Sigma, USA) 0.4 $\%(\mathrm{w} / \mathrm{v})$ was incubated at $37{ }^{\circ} \mathrm{C}$ for 30 minutes. The reaction was stopped by adding $400 \mu \mathrm{l}$ of dinitrosalicylic acid (DNS) reagent and then the mixture was heated in boiling water for 10 minutes. After cooled, reaction solution was appropriately diluted with distilled water and the absorbance was measured at $540 \mathrm{~nm}$. $\beta$-1,3-glucanase activity was determined as the amount of reducing sugar released from laminarin hydrolysis. A standard curve was built by using glucose and $\beta$-1,3-glucanase activity was expressed as units per milligram of total protein, where one unit is defined as the enzyme activity that catalyzes the formation of $1 \mu$ mol glucose per minute at $37^{\circ} \mathrm{C}$.

Chitinase activity was determined by dinitrosalicylic acid method with slight modifications. Chitin (Sigma, USA) was dissolved in sodium phosphate buffer $(0.05 \mathrm{M}, \mathrm{pH} 5.2)$ and shaken at $500 \mathrm{rpm}$ for 30 minutes. A $100 \mu \mathrm{l}$ of 1 $\%$ (w/v) colloidal chitin plus $100 \mu \mathrm{l}$ of enzyme extract solution was shaken at $500 \mathrm{rpm}$ at $37{ }^{\circ} \mathrm{C}$ in a thermostatic shaker for 1 hour. The reaction was stopped by heating in boiling water for 20 minutes. Then, the mixture was centrifuged at $10000 \mathrm{rpm}$ for 5 minutes and the supernatant was collected to measure chitinase activity. The mixture consisted of $100 \mu \mathrm{l}$ supernatant and $100 \mu \mathrm{l}$ DNS reagent was heated in boiling water for 10 minutes. The solution was appropriately diluted and the absorbance was measured at $535 \mathrm{~nm}$. A standard curve was constructed by using N-Acetyl-D-Glucosamine and chitinase activity was expressed as units per milligram of total protein, where as one unit is defined as the amount of enzyme required to release $1 \mu \mathrm{mol}$ of N-Acetyl-D-Glucosamine per minute from chitin hydrolysis under the assay conditions (Dai, Hu, Huang, \& Li, 2011).

The total soluble protein content was determined according to the method of Bradford (1976) using bovine serum albumin as the standard.

\subsection{Statistical Analysis}

All experiments were carried out in a completely randommized design with five replications per treatment. Analysis of variance and differences between means by Duncan's multiple-range test were determined using the SAS software (SAS Institute, version 9.1.3, USA). 


\section{Results}

\subsection{Fungal Isolation}

The fungus grew slowly on PDA medium. The mycelial touched the edge of Petri dishes $(6 \mathrm{~cm}$ in diameter $)$ after 14 days incubation at $25^{\circ} \mathrm{C}$. The colonies were powdery, green or greyish olive. Under the microscope, conidia was cylindrical and elliptical, smooth and with thick wall, one or two branches. The sequencing result of 28s rRNA gene was blasted on NCBI and indicated 100\% homology with Penicilliumdigitatum DAOM 226633.

\subsection{In vitro Antifungal Assay of WSC Against P. digitatum $\mathrm{P} 4$}

\subsubsection{Effect of WSC on Spore Germination of P. digitatum $\mathrm{P} 4$}

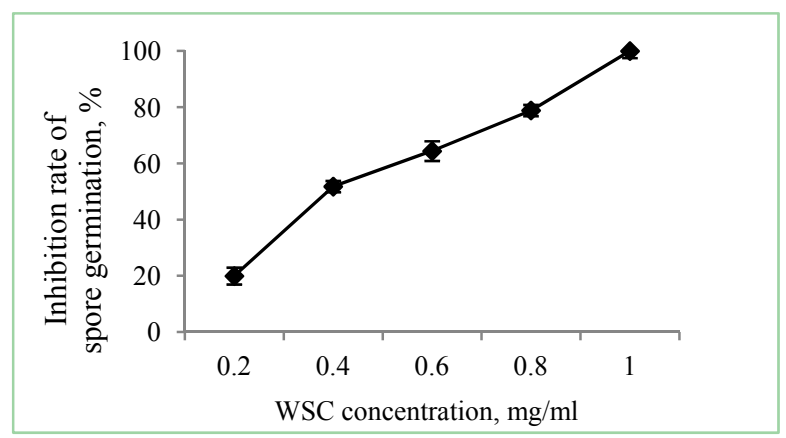

Figure 1. Inhibitory effect of various WSC concentrations on the germination of $P$. digitatum $\mathrm{P} 4 \mathrm{after} 24 \mathrm{~h}$ inoculation at $25^{\circ} \mathrm{C}$. The vertical bar indicates the standard error of means of five replicates

As shown by the results in figure 1, rate of spore germination of $P$. digitatum $\mathrm{P} 4$ was much reduced by WSC. The inhibition percentage increased with the increase in WSC concentration. After $24 \mathrm{~h}$ incubation at $25^{\circ} \mathrm{C}$, there was no inhibition of germination in control slides and $100 \%$ inhibition was found at $1 \mathrm{mg} / \mathrm{ml} \mathrm{WSC}$ concentration. The $\mathrm{EC}_{50}$ and $\mathrm{MIC}_{90}$ were calculated based on the obtained correlation coefficients $\left(\mathrm{R}^{2}=0.97\right)$. The results showed that $\mathrm{EC}_{50}$ and $\mathrm{MIC}_{90}$ values were 0.46 and $0.89 \mathrm{mg} / \mathrm{ml} \mathrm{WSC}$, respectively.

\subsubsection{Effect of WSC on Mycelial Radial Growth}

WSC significantly inhibited mycelial radial growth of $P$. digitatum $\mathrm{P} 4$ at all tested concentrations (Figure 2). The inhibitory effect of WSC was concentration-dependent mode. Complete inhibition of mycelial growth was obtained at $1 \mathrm{mg} / \mathrm{ml}$ WSC concentration.

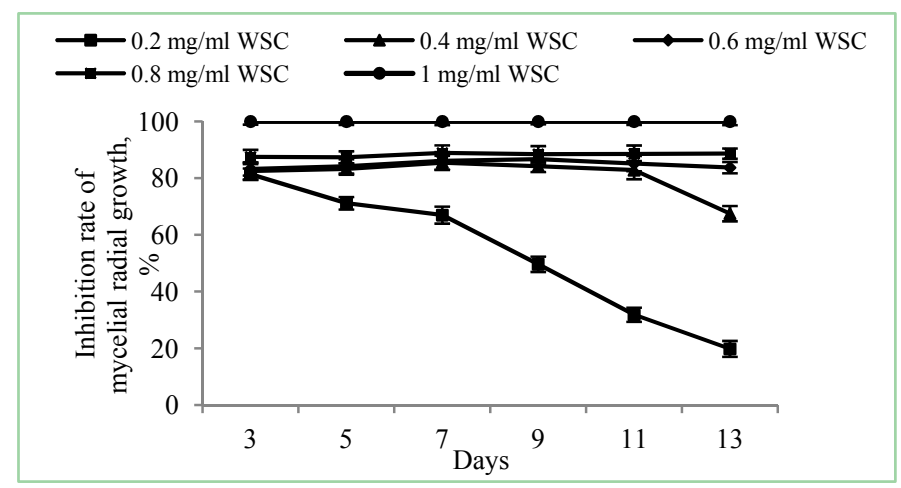

Figure 2. Inhibitory effect of various WSC concentrations on mycelial radial growth of $P$. digitatum $\mathrm{P} 4$ at $25^{\circ} \mathrm{C}$. The vertical bar indicates the standard error of means of five replicates 


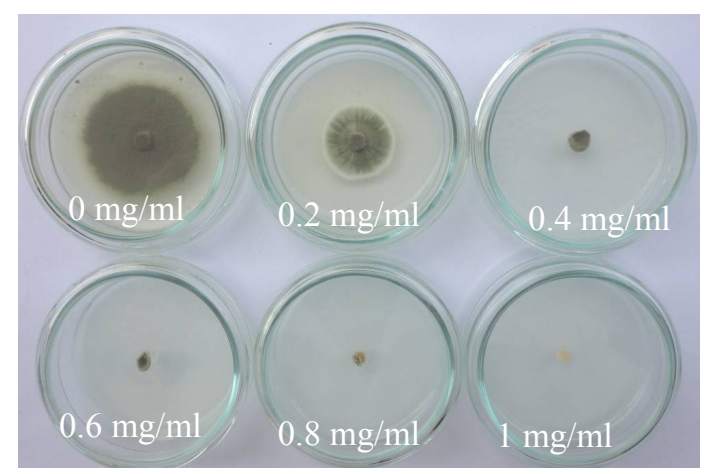

Figure 3. Effect of various concentrations of WSC on P. digitatum P4 colony morphology after 9 days incubation at $25{ }^{\circ} \mathrm{C}$

P. digitatum P4 was affected not only mycelial radial but also colony morphology by the WSC. Colonies of tested plates were underdeveloped, thinner and with lighter color than colonies of control plates on PDA medium. Colonies surfaces were shrunken, yellowed, dried and nearly peeled off original mycelial plug at the higher concentrations $(0.8 \mathrm{mg} / \mathrm{ml}$ and $1 \mathrm{mg} / \mathrm{ml})$ (Figure 3).

\subsubsection{Effect of WSC on Mycelial Growth in Broth Culture}

The addition of WSC into the PDB medium inhibited mycelial growth of P. digitatum P4 at all different concentrations. The higher concentration of WSC, the clearer cultures and the higher inhibitory effects (Figure 4 and Figure 5). After 14 days, WSC concentrations inhibiting $50 \%$ and $90 \%$ of mycelial growth were $0.22 \mathrm{mg} / \mathrm{ml}$ and $0.85 \mathrm{mg} / \mathrm{ml}\left(\mathrm{R}^{2}=0.94\right) .100 \%$ inhibition of P. Digitatum $\mathrm{P} 4$ development was also observed at $1 \mathrm{mg} / \mathrm{ml}$ WSC concentration.

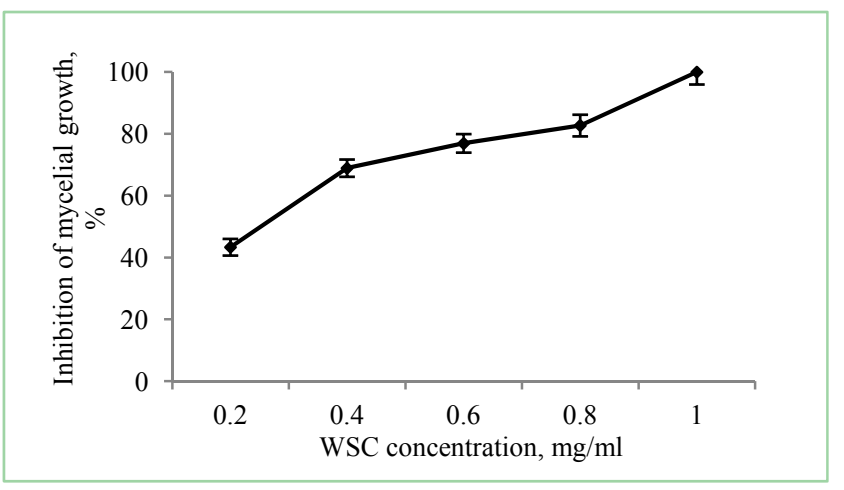

Figure 4. Effect of WSC of various concentrations on mycelial growth of $P$. digitatum P4 in PDB medium after 14 days incubation at $25^{\circ} \mathrm{C}$. The vertical bar indicates the standard error of means of five replicates

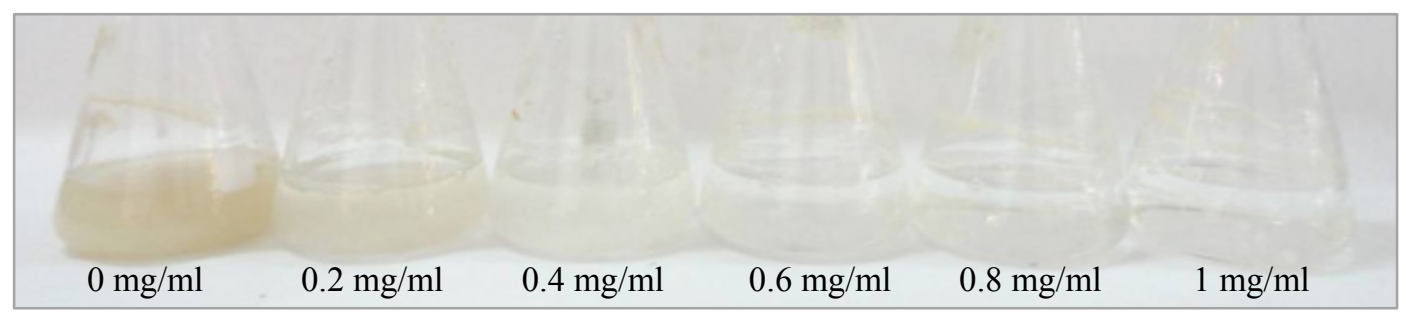

Figure 5. Effect of various WSC concentrations on the biomass of P. digitatum $\mathrm{P} 4$ after 14 days incubation at $25^{\circ} \mathrm{C}$ 


\subsection{In vivo Antifungal Assay of WSC Against Green Mould Disease}

The in vivo effects of WSC in controlling green moud disease on the basis oflesion diameter of oranges inoculated with $P$. digitatum P4 were demonstrated in Figure 6 . This criteria was significantly reduced by all WSC doses. The disease control effects of WSC were also concentration-dependent.

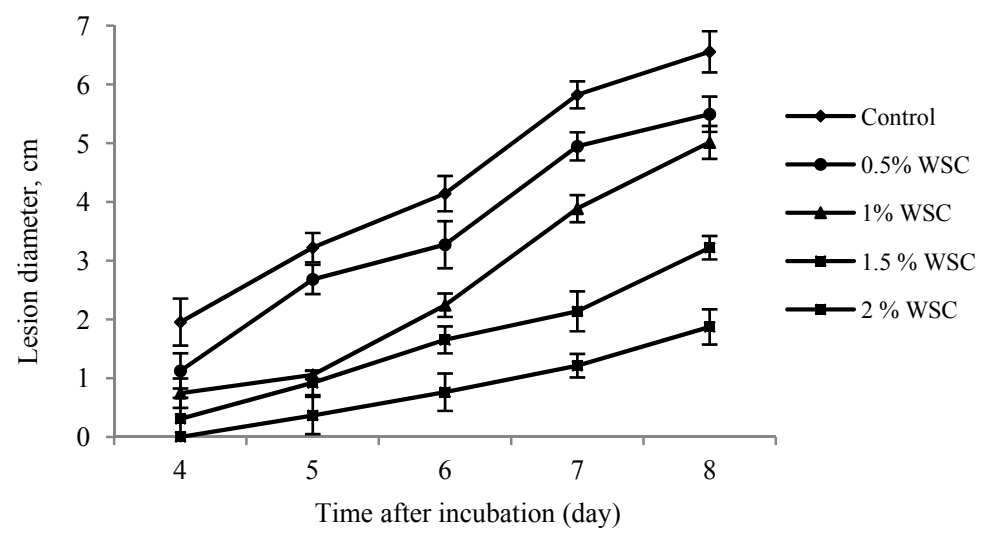

Figure 6. Effect of WSC on lesion diameter of green mould disease on orange fruits (at $25^{\circ} \mathrm{C}$ ). The vertical bar indicates the standard error of means of five replicates

The earliest symptom of green mould disease occurred after $72 \mathrm{~h}$ inoculation at $25{ }^{\circ} \mathrm{C}$ in control fruits with white water-soaked spot which gradually turned into green mould. Visible symptoms of treated fruits mainly occurred after $96 \mathrm{~h}$, so the lesion diameter was recorded after this time. In general, at the sameobservation time, thehigher WSC concentration, the lower disease incidence and the smaller lesion diameter. All surfaces of control fruits were coated by $P$. digitatum $\mathrm{P} 4$ on $8^{\text {th }}$ day of storage while lesion diameters of fruits treated with WSC were more lower. The diameters of the lesion on oranges coated by $0.5 \%, 1.0 \%, 1.5 \%$, and $2.0 \%$ WSC after 8 days were $5.49 \mathrm{~cm}, 5.01 \mathrm{~cm}, 3.22 \mathrm{~cm}$, and $1.87 \mathrm{~cm}$ much smaller, respectively, than that on control fruits.

\subsection{Determination of Defense-Related Enzymes: Chitinase and $\beta$-1,3-Glucanase}
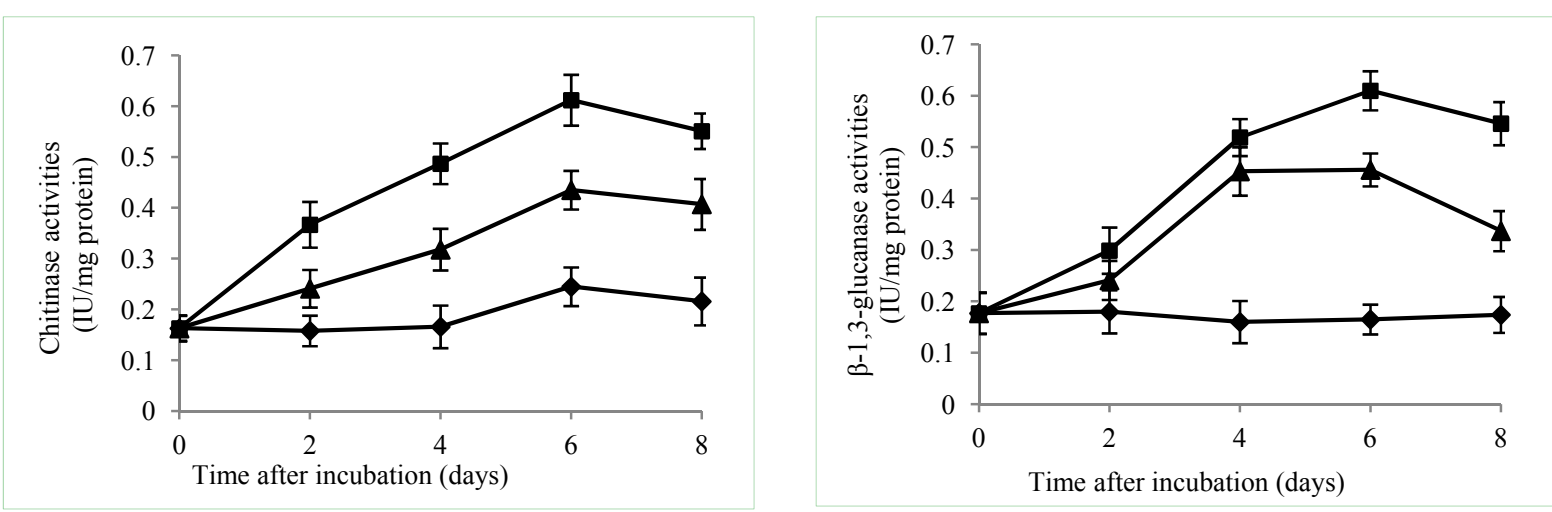

Figure 7. Effects of WSC on the activities of chitinase and $\beta$-1,3-glucanase of orange fruits:

$\rightarrow$ Control; - Inoculated, treated with $2 \%$ WSC; $\rightarrow$ Inoculated;

The vertical bar indicates the standard error of means of five replicates 
As is seen from Figure 7, chitinase and $\beta$-1,3-glucanase activities were induced in both inoculated treatment and inoculated, treated with WSC treatment. In general, almost a similar trend was observed in these enzymes and the increasing activities peaked on the $6^{\text {th }}$ day after treatment. Flavedo tissue of inoculated and treated with WSC treatment had the highest enzymatic activity compared to the control and the fruits challenged with $P$. digitatum P4 only. Besides, these enzyme activities in inoculated treatment were higher than control. For example, after 4 days treatment, chitinase of control, inoculated only and inoculated and treated with WSC treatment were 0.166 $\mathrm{IU} / \mathrm{mg}$ protein, $0.318 \mathrm{IU} / \mathrm{mg}$ protein, $0.487 \mathrm{IU} / \mathrm{mg}$ protein, respectively. Similarly, for $\beta-1,3$ - glucanase, these activities were $0.160 \mathrm{IU} / \mathrm{mg}$ protein, $0.453 \mathrm{IU} / \mathrm{mg}$ protein and $0.519 \mathrm{IU} / \mathrm{mg}$ protein, respectively.

\section{Discussion}

Chitosan and its derivatives are believed to be the effective natural fungicides due to their antimicrobial and elicitation activities (Ben-Shalom, Ardi, Pinto, Aki, \& Fallik, 2003; Xu et al., 2007). In this work, the in vitro results demonstrated that spore germination, mycelial growth and colony morphology of $P$. digitatum $\mathrm{P} 4$ were affected by the WSC. All of the in vitro results showed that the complete inhibition of $P$. digitatum $\mathrm{P} 4$ growth was obtained at $1 \mathrm{mg} / \mathrm{ml}$ WSC concentration. Besides, at the same doses of WSC, the obtained inhibitory effect in broth cultures was higher than others. This maybe due to the fungus which was easier to expose to antifungal agent in liquid medium than that insolid medium. The similar results were also recorded in other fungi such as Fusarium oxysporum f. sp. cubense (Al-Hetar et al., 2010), Alternaria kikuchiana Tanaka, Physalospora piricola (Meng et al., 2010), Collectotrichum sp. (Ali, Muhammad, Sijam, \& Siddiqui, 2010; Jitareerat et al., 2007; Muñoz, Moret, \& Garcés, 2009). The general trend of these results was the percentage of inhibition increased with the increase in WSC concentrations. The in vitro antifungal actitivity of chitosan and its derivatives can be explained by at least three mechanisms. First, WSC possesses mainly amino groups in its structure (Kim \& Rajapakse, 2005). So, because of its polycationic nature, it interferes with negatively charged residues of fungal cell wall surface (Al-Hetar et al., 2010). This interaction can alter permeability characteristics of fungal cell membrane and further prevent the entry of materials or lead to the leakage of intracellular electrolytes and proteinaceous constituents that finally causes the death of fungi (Kim \& Rajapakse, 2005). Second, other suggested mechanism for antifungal activity of WSC is the interaction of diffused hydrolysis products with fungal DNA as WSC penetrates the fungal cell. This leads to the inhibition of the normal synthesis of mRNA and protein (Badawy \& Rabea, 2009). Finally, the deprivation of metals, trace elements of essential nutrients by chelating action of WSC has also been considered as a reason that inhibits the growth of fungi (Al-Hetar et al., 2010; Bautista-Baños et al., 2006; Kim \& Rajapakse, 2005).

Inoculation of citrus fruits with Penicillium digitatum considerably affected the D-galacturonic acid content of the peel. During the infection process, the fungus produces exo-polygalacturonase, which hydrolyzes the cell wall pectin into monomers of galacturonic acid, which is responsible for cell disintegration and tissue maceration (Barkai-Golan, 2001). In this study, the in vivo results indicated that WSC was effective in controlling green mould disease. WSC coating was able to delay the onset of disease symptoms, reduce the diameter of lesions and slow down the disease progress.

In addition to direct antifungal mechanisms (in vitro), three mechanisms were added to explain for the in vivo antifungal effect of WSC. First, when applied as a coating, WSC may form a semi-permeable film which can regulate the gas exchange, slow down ethylene production and respiration. This effect of WSC to delay senescence processes probably reduces decay incidence indirectly. Second, other supporting explanation for indirect antifungal effect of WSC is WSC film can reduce the production of polygalacturonase by the pathogen and cause severe cytological damage to invading hyphae. Third, WSC application may simultaneously induce the formation of antifungal hydrolases, such as chitinase and $\beta$-1,3-glucanase, which are able to the reduction in major components of fungal cell walls. This may lead to the restriction of the fungal colonization development and reduction in maceration area of host tissue. Therefore, by inducing and accelerating chitinase and glucanase, WSC may delay the reactivation of latent infections, which naturally occurs as host tissue resistant declines (Barkai-Golan, 2001).

Modes of action of chitosan and its derivatives in controlling postharvest disease based on antifungal and elicitation abilities were demonstrated in many other researches. The reduction in disease incidence and lesion diameter and the inducement of chitinase and $\beta$-1,3-glucanase by chitosan application were also recorded in pear fruits (Meng et al., 2010), tomato and grape (Muñoz et al., 2009), papaya (Ali et al., 2010), mango (Jitareerat et al., 2007). For citrus fruits, Fajardo et al. (1998) reported that chitinase and $\beta$-1,3-glucanase were enhanced by separate application of chitosan and P. digitatum infection. However, there was no significant difference of these enzymes between these two challenges during 5 days observation, except on $4^{\text {th }}$ day after treatment. The results indicated that chitosan-treated fruits had lower disease incidence and higher enzyme activities than the control. 


\section{Conclusion}

The current study indicated that WSC could inhibit the growth of P. digitatum $\mathrm{P} 4$ in vitro and in vivo. The antifungal effects were concentration-dependent mode. The reduction of green mould disease is likely the results of a multi-mode of action. Based on these findings, WSC was considered a promising natural alternative to synthetic fungicide in postharvest disease of orange fruits. Moreover, study demonstrated that WSC has the potential as a natural elicitor by inducing defense-related enzymes in flavedo tissue.

\section{References}

Abeles, F. B., \& Forrence, L. E. (1970). Temporal and hormonal control of b-1,3-glucanase in Phaseolus vulgaris. Plant Physiology, 45, 395-400.

Al-Hetar, M. Y., Zainal Abidin, M. A., Sariah, M., \& Wong, M. Y. (2010). Antifungal activity of chitosan against Fusarium oxysporum f. sp. cubense. Journal of Applied Polymer Science, 120(4), 2434-2439. http://dx.doi.org/10.1002/app.33455

Ali, A., Muhammad, M. T. M., Sijam, K., \& Siddiqui, Y. (2010). Potential of chitosan coating in delaying the postharvest anthracnose (Colletotrichum gloeosporioides Penz.) of Eksotika II papaya. International Journal of Food Science \& Technology, 45(10), 2134-2140. http://dx.doi.org/10.1111/j.1365-2621.2010.02389.x

Anonymous. (2012). Food and Agriculture Organization Statistic.

Badawy, M. E. I., \& Rabea, E. I. (2009). Potential of the biopolymer chitosan with different molecular weights to control postharvest gray mold of tomato fruit. Postharvest Biology and Technology, 51(1), 110-117. http://dx.doi.org/10.1016/j.postharvbio.2008.05.018

Barkai-Golan, R. (2001). Postharvest diseases of fruits and vegetables: Development and control. Elsevier Science B.V.

Bautista-Baños, S., Hernández-Lauzardo, A. N., Velázquez-del Valle, M. G., Hernández-López, M., Ait Barka, E., Bosquez-Molina, E., \& Wilson, C. L. (2006). Chitosan as a potential natural compound to control pre and postharvest diseases of horticultural commodities. Crop Protection, 25(2), 108-118. http://dx.doi.org/10.1016/j.cropro.2005.03.010

Ben-Shalom, N., Ardi, R., Pinto, R., Aki, C., \& Fallik, E. (2003). Controlling gray mould caused by Botrytis cinerea in cucumber plants by means of chitosan. Crop Protection, 22(2), 285-290. http://dx.doi.org/10.1016/S0261-2194(02)00149-7

Bradford, M. M. (1976). A rapid and sensitive method for the quantitation ofmicrogram quantities of protein utilizing the principle of protein-dye binding. Analytical Biochem, 72, 248-254. http://dx.doi.org/10.1016/0003-2697(76)90527-3

Cao, J., \& Jiang, W. (2006). Induction of resistance in Yali pear (Pyrus bretschneideri Rehd.) fruit against postharvest diseases by acibenzolar-S-methyl sprays on trees during fruit growth. Scientia Horticulturae, 110(2), 181-186. http://dx.doi.org/10.1016/j.scienta.2006.07.002

Cronin, M. J., Yohalem, D. S., Harris, R. F., \& Andrews, J. H. (1996). Putative mechanism and dynamics of inhibition of the apple scab pathogen Venturia inaequalis by compost extracts. Soil Biology and Biochemistry, 28(9), 1241-1249. http://dx.doi.org/10.1016/0038-0717(96)00131-9

Dai, D., Hu, W., Huang, G., \& Li, W. (2011). Purification and characterization of a novel extracellular chitinase from thermophilic Bacillus sp. Hu1. African Journal of Biotechnology 10(13), 2476-2485.

Fajardo, J. E., McCollum, T. G., McDonald, R. E., \& Mayer, R. T. (1998). Differential induction of proteins in orange flavedo by biologically based elicitors and challenged by Penicillium digitatum Sacc. Biological Control, 13(3), 143-151. http://dx.doi.org/10.1006/bcon.1998.0661

Hernández-Lauzardo, A. N., Valle, M. G. V., \& Guerra-Sánchez, M. G. (2011). Current status of action mode and effect of chitosan against phytopathogens fungi. African Journal of Microbiology Research, 5(25), 4243-4247. http://dx.doi.org/10.5897/AJMR11.104

Jitareerat, P., Paumchai, S., Kanlayanarat, S., \& Sangchote, S. (2007). Effect of chitosan on ripening, enzymatic activity, and disease development in mango (mangifera indica) fruit. New Zealand Journal of Crop and Horticultural Science, 35(2), 211-218. http://dx.doi.org/10.1080/01140670709510187

Kim, S.-K., \& Rajapakse, N. (2005). Enzymatic production and biological activities of chitosan oligosaccharides 
(COS): A review. Carbohydrate Polymers, 62(4), 357-368. http://dx.doi.org/10.1016/j.carbpol.2005.08.012

Korsten, L., \& Taverner, P. (2012). Citrus. In Rees, D., Farrell, G., \& Orchard, J. (Eds.), Crop Post-Harvest: Science and Technology (pp. 43-79). http://dx.doi.org/10.1002/9781444354652

Long, L. T., Thao, N. T. P., Trung, T. S., \& Boi, V. N. (2013). Optimization of preparation of water-soluble chitosan and its antibacterial ability on E. coli. J. Fisheries Sci. and Technol., 2, 20-27.

Meng, X., Yang, L., Kennedy, J. F., \& Tian, S. (2010). Effects of chitosan and oligochitosan on growth of two fungal pathogens and physiological properties in pear fruit. Carbohydrate Polymers, 81(1), $70-75$. http://dx.doi.org/10.1016/j.carbpol.2010.01.057

Muñoz, Z., Moret, A., \& Garcés, S. (2009). Assessment of chitosan for inhibition of Colletotrichum sp. on tomatoes and grapes. Crop Protection, 28(1), 36-40. http://dx.doi.org/10.1016/j.cropro.2008.08.015

Naqvi, S. A. M. H. (2004). Diseases of Fruits and Vegetables: Diagnosis and management of pre and post-harvest diseases of citrus fruit (pp. 339-359).

Narayanasamy, P. (2006). Postharvest pathogens and disease management. http://dx.doi.org/10.1002/0471751987

$\mathrm{Xu}$, J., Zhao, X., Han, X., \& Du, Y. (2007). Antifungal activity of oligochitosan against Phytophthora capsici and other plant pathogenic fungi in vitro. Pesticide Biochemistry and Physiology, 87(3), 220-228. http://dx.doi.org/10.1016/j.pestbp.2006.07.013

Yan, J., Li, J., Zhao, H., Chen, N., Cao, J., \& Jiang, W. (2011). Effects of oligochitosan on postharvest Alternaria rot, storage quality, and defense responses in Chinese jujube (Zizyphus jujuba Mill. cv. Dongzao) fruit. $J$. Food Prot., 74(5), 783-788. http://dx.doi.org/10.4315/0362-028x.jfp-10-480

\section{Copyrights}

Copyright for this article is retained by the author(s), with first publication rights granted to the journal.

This is an open-access article distributed under the terms and conditions of the Creative Commons Attribution license (http://creativecommons.org/licenses/by/3.0/). 